\title{
Exploring Deep Content in Physical Rehabilitation Games
}

\author{
Niels Quinten ${ }^{12}$, Steven Malliet ${ }^{2}$, and Karin Coninx ${ }^{1}$ \\ 1 University of Hasselt, Martelarenlaan 42, 3500 Hasselt, Belgium \\ ${ }^{2}$ LUCA School of Arts, C-Mine 5, 3600 Genk, Belgium
}

\begin{abstract}
This paper argues that game mechanics are important tools to combine rehabilitation therapy concerns with immersive game play. Through the practical design of a game we describe how properties of game mechanics (actions, attributes, dynamics, rules, space, and skill/chance) connect to elements of rehabilitation therapy (exercise motion, parameters, therapy context, goals, motion trajectory, and motion constraints). We aim to stimulate rehabilitation game researchers to consider applying the presented approach in their own designs.
\end{abstract}

Keywords: Game Design, Physical Rehabilitation, Deep Content, Design Research, Game Mechanics, Game Conventions

\section{Introduction}

This study draws on theories developed in serious game design and applies these to the creation of a game for physical rehabilitation. Specifically we address the contstruct of deep content, defined by Isbister, et al., [1, p. 2043] as content that is tightly connected to a game's structure and is experienced as an integral part of the game.

\section{Deep Content in Physical Rehabilitation Games}

\subsection{Physical Rehabilitation Exercises}

Physical rehabilitation therapy is particularly effective when patients perform physical exercises repetitively and intensively [2]. Thus, an opportunity lies in matching these physical exercises with a virtual environment where the repetition of physical challenges results in winning [3]. Pery, et al. [3] note that rehabilitation games often fail to meet these expectations. Only a small amount of studies on games for rehabilitation are concerned with the close integration of rehabilitation and games, as most highlight only one of both topics [4]. 


\subsection{Patient Disabilities}

Designers of rehabilitation games have to consider patient disability resulting from cognitive [5], physical [6] and visual [7] impairments. In order for a customized game play to emerge, these impairments need to be incorporated as essential elements in design process rather than as external goals. This implies that designers of rehabilitation games cannot simply create adaptations of exisiting games, but should experiment with formats that are tailored to this specific context. For instance, Notelaers, et al. [8] note that the game interface should be adapted to accommodate patient disabilities by avoiding several elements that are common in commercial games. Vanden Abeele et al. [9] developed a design style that makes players understand the underlying game structure more easily and is simultaneously aesthetically pleasing.

\section{Research Questions}

While these are a few examples which cover the close integration of rehabilitation therapy and digital games, these often lack the situational knowledge needed to transfer research into practical design solutions [10]. In order to support the practical creation of physical rehabilitation games, we investigate how we can practically use the concept of deep content in the development of such a game. The following two research questions are formulated:

1. Which game design elements support the practical integration of rehabilitation exercises and game mechanics, for deep content to emerge?

2. How do patient impairments influence the design process when creating deep content in rehabilitation games?

\section{Exploring Deep Content Through the Design of a Digital Rehabilitation Game Prototype}

A digital game prototype was developed in which rehabilitation exercises and patient impairments have been integrated. A process of interaction or 'conversation' between the artist and the material of digital games took place, which is an essential requirement of design research [10].

\subsection{Rehabilitation Components}

In order to include rehabilitation exercises in the game mechanics, the approach of Octavia, et al. [11] was followed, with integration of several simple motions (e.g. horizontal, vertical and circular) that need to be performed with the most affected upper-limb. The following impairments were accounted for:

- Reduced dexterity (e.g. inability to use small buttons);

- Visual difficulties (e.g. inability to visually perceive a game world); 
- Memory and cognitive processing problems (e.g. understanding the complexities of a game).

The Novint Falcon was selected as input device, allowing patients to move their hand in three dimensions $(10 \mathrm{~cm}$ in each direction). The Unity3D game engine version 3.X was used to develop the prototype.

\subsection{The Game Play of Flower Garden}

In the resulting game, Flower Garden (see Fig. 1), patients grow and maintain flowers by performing simple rehabilitation exercises. All flowers created by singular players are placed in a virtual garden that is shown on a large screen in a public room of the rehabilitation centre. The goal of the game is to keep the flowers healthy, which depends on how well the predefined exercises are performed. Players design their own flowers by executing four main virtual actions: planting seeds, growing plants, healing plants, and coloring flowers. In real-life, these actions translate to the motions defined above. For instance, in order to plant a seed and color a flower, players complete the circular motions indicated by dashed lines. The average precision of the player while tracing a line is taken into account and has an impact on the health of the flower.

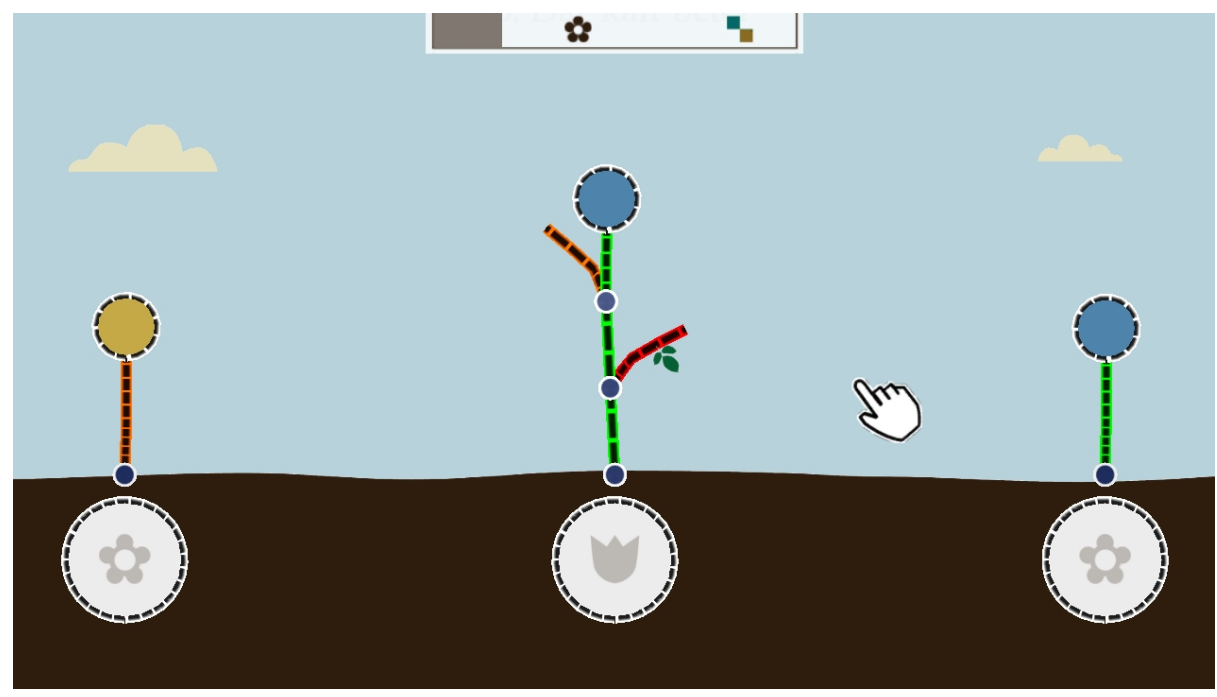

Fig. 1. In-game screenshot of 'Flower Garden' with three seeds and two types of flowers. 


\section{$5 \quad$ Results}

\subsection{Therapy Exercises and Game Mechanics}

Flower Garden includes three main mechanics: planting seeds, growing/healing plants, and coloring flowers. As illustrated in Table 1, game mechanics possess six properties - actions, attributes, dynamics, rules, space, and skill/chance [12] - that structurally connect the rehabilitation world to formal game elements. First, the rehabilitation motions and their parameters are connected to the virtual world by using the properties 'actions' and 'attributes'. For instance, executing a horizontal motion in real-life represents growing a plant in the virtual environment. How well this motion is performed defines the value of the attributes.

Table 1. An overview of how game mechanics link the rehabilitation world and the game world

\begin{tabular}{|c|c|c|}
\hline Game Mechanics & $\begin{array}{l}\text { Rehabilitation } \\
\text { World }\end{array}$ & Game World \\
\hline \multicolumn{3}{|l|}{ Physical Components } \\
\hline \multirow[t]{2}{*}{ Actions } & $\begin{array}{l}\text { Horizontal motion } \\
\text { Vertical motion }\end{array}$ & $\begin{array}{l}\text { Planting a flower } \\
\text { Healing a flower }\end{array}$ \\
\hline & Circular motion & $\begin{array}{l}\text { Planting a seed } \\
\text { Coloring a flower }\end{array}$ \\
\hline Attributes & Quality of motion & $\begin{array}{l}\text { Flowers' health } \\
\text { flowers' type flowers' } \\
\text { color }\end{array}$ \\
\hline Space & Motion trajectory & $\begin{array}{l}\text { Seed Shape Plant } \\
\text { Shape Flower Shape }\end{array}$ \\
\hline Rules & $\begin{array}{l}\text { Be precise while } \\
\text { completing the } \\
\text { trajectory }\end{array}$ & $\begin{array}{l}\text { Make a healthy } \\
\text { flower } \\
\text { Grow a plant } \\
\text { Color a flower }\end{array}$ \\
\hline Skills vs. chance & $\begin{array}{l}\text { Adherence to a } \\
\text { predefined trajectory }\end{array}$ & $\begin{array}{l}\text { Create flowers } \\
\text { according to your } \\
\text { own taste }\end{array}$ \\
\hline \multicolumn{3}{|l|}{ Contextual Components } \\
\hline Dynamics & $\begin{array}{l}\text { Multiple sessions } 5 \\
\text { to } 10 \text { minutes of play } \\
\text { time }\end{array}$ & Brief actions \\
\hline
\end{tabular}




\subsection{Patient Impairments and the Virtual World}

Flower Garden is a Construction and Management Game in which players progress by gradually earning and adding more virtual objects to a game world or model. As a result, the concept has a degree of cognitive and visual complexity that patients may not be able to deal with. We experienced a number of difficulties with regards to the patient impairments, including the use of an inventory system. Inventory systems can increase the visual complexity of the screen and the difficulty of the hand-eye coordination. In an attempt to resolve this, we integrated the inventory system into the action of planting a seed, both visually and functionally. Each time players plant a new seed, a new icon appears in the center of the seed's circle (see Fig. 1). Players can thus browse through the flowers automatically when planting a seed. This has the disadvantage that players are not able to see all available flowers at the same time, and the system would likely not be sustainable when more flowers were added.

\section{Implications of Deep Content in Rehabilitation Games}

The value of these results does not reside in the identification of game mechanics per se, but in the fact that these connect the game's content to its formal characteristics. In this manner, the mechanics become practical tools with which game designers and rehabilitation therapists can bridge the gap between their respective domains. Designers and therapists can, for instance, investigate which mechanics they want to include to facilitate rehabilitation exercises and how to do this.

In the prototype we designed, the virtual world and the interface were closely connected to the game's genre. Because we selected a specific genre in the beginning of the design process, undesirable entertainment game conventions were unconsciously included in the prototype. While the surface components (e.g. interface) could be adapted to patients relatively easily, the genre conventions underlying these components might be much harder to modify. Therefore, working with predefined concepts is not necessarily the most feasible solution for rehabilitation game design.

\section{Conclusion}

This paper raised two questions. The first question was how rehabilitation exercises and formal game qualities can be practically integrated in a rehabilitation game in order for deep content to emerge. The mechanics constituting our prototype contained a number of practical design components that were linked to essential parts of rehabilitation exercises. Game mechanics thus provided a conceptual tool to relate digital games to rehabilitation therapy. The second question was how patient disabilities can be taken into account during the design of a rehabilitation game in order for deep content to emerge. In our design, 
conventions of existing entertainment games unobtrusively slipped into the concept of a rehabilitation game. These conventions can potentially conflict with the disabilities of patients and should be treated with caution.

Acknowledgement: This work was supported by Hasselt University and

LSM under Grant KOS 13 KM LS 225.

\section{References}

1. K. Isbister, M. Flanagan, and C. Hash, "Designing games for learning: insights from conversations with designers," in Proceedings of the SIGCHI Conference on Human Factors in Computing Systems, (Atlanta, Georgia, USA), pp. 2041-2044, ACM, 2010.

2. P. Langhorne, F. Coupar, and A. Pollock, "Motor recovery after stroke: a systematic review," The Lancet Neurology, vol. 8, no. 8, pp. 741-754, 2009.

3. J. C. Perry, J. Andureu, F. I. Cavallaro, J. Veneman, S. Carmien, and T. Keller, "Effective game use in neurorehabilitation: user-centered perspectives," in Handbook of Research on Improving Learning and Motivation through Educational Games (P. Felicia, ed.), pp. 683-725, Hershey, PA, USA: IGI Global, 2011.

4. N. Quinten and S. Malliet, "Considering Design Concerns in Games for Physical Rehabilitation," in Interactive Technologies and Games 2011 Conference Proceedings, (Nothingham, GB), pp. 132-145, 2011.

5. S. Zinn, H. B. Bosworth, H. M. Hoenig, and H. S. Swartzwelder, "Executive function deficits in acute stroke," Archives of Physical Medicine and Rehabilitation, vol. 88, pp. 173-180, Feb. 2007.

6. L. Ada and C. Canning, "Changing the way we view the contribution of motor impairments to physical disability after stroke," in Science-Based Rehabilitation (K. Refshauge, L. Ada, and E. Ellis, eds.), pp. 87-106, Edinburgh: ButterworthHeinemann, 2005.

7. F. Rowe, D. Brand, C. A. Jackson, A. Price, L. Walker, S. Harrison, C. Eccleston, C. Scott, N. Akerman, C. Dodridge, C. Howard, T. Shipman, U. Sperring, S. MacDiarmid, and C. Freeman, "Visual impairment following stroke: do stroke patients require vision assessment?," Age and Ageing, vol. 38, pp. 188-193, Nov. 2008.

8. S. Notelaers, T. De Weyer, K. Robert, C. Raymaekers, and K. Coninx, "Design Aspects for Rehabilitation Games for MS Patients," in Proceedings of Design and Engineering of Game-like Virtual and Multimodal Environment, (Berlin, Germany), 2010.

9. V. Vanden Abeele, L. Geurts, J. Husson, F. Windey, J. H. Annema, M. Verstraete, and S. Desmet, "Designing Slow Fun! Physical Therapy Games to Remedy the Negative Consequences of Spasticity," in Proceedings of the 3rd International Conference on Fun and Games, (Leuven, Belgium), pp. 1-2, ACM, 2010.

10. N. Cross, Designerly ways of knowing. London: Springer, 2006.

11. J. R. Octavia, K. Coninx, and P. Feys, "As I am not you: accommodating user diversity through adaptive rehabilitation training for multiple sclerosis patients," in Proceedings of the 24th Australian Computer-Human Interaction Conference (V. Farrell, G. Farrell, C. Chua, W. Huang, R. Vasa, and C. Woodward, eds.), (Melbourne, VIC, Australia), pp. 424-432, ACM, 2012.

12. J. Schell, The Art of Game Design: A Book of Lenses. San Francisco, CA, USA: Morgan Kaufmann Publishers Inc., 2008. 